\section{Psicologia Escolar \\ e Educacional}

ARTIGO

DOI: http://dx.doi.org/1 10.1590/2175-35392021221612

Localizador - e221612

\title{
EXPLORAÇÃO SEXUAL DE CRIANÇAS E ADOLESCENTES: REFLEXÃO SOBRE O PAPEL DA ESCOLA
}

\author{
Denise Carvalho Campos $^{1} \mathbb{D}$; Lílian Caroline Urnau ${ }^{2} \mathbb{D}$
}

\section{RESUMO}

Este artigo analisa o papel da escola no enfrentamento da Exploração Sexual de Crianças e Adolescentes, com base em um estudo realizado em unidades de ensino da rede pública estadual de Porto Velho-RO, município que nos últimos anos convive com as consequências sociais da construção de usinas hidrelétricas no Rio Madeira. A investigação foi desenvolvida por meio de entrevistas semiestruturadas, da qual participaram 20 agentes escolares, vinculados a quatro instituições de ensino. A análise das informações foi realizada à luz de referenciais críticos sobre direitos humanos, educação e psicologia, por meio da construção de categorias e subcategorias. Os resultados revelam que a maioria dos agentes escolares desconhece a problemática e que nenhuma das escolas pesquisadas desenvolve ações de enfrentamento. A educação sexual não é trabalhada como um tema transversal e a sexualidade é reduzida ao enfoque do risco e vitimização, não entendida sob a perspectiva dos direitos humanos.

Palavras-chave: violência sexual; crianças e adolescentes; escola.

\section{Sexual Exploitation of Children and Adolescents: a reflection of the role played by schools}

\begin{abstract}
This article analyzes the school's role on tackling the sexual exploitation of children and adolescents, based on a study carried out in state schools of Porto Velho - RO, a municipality that in recent years has been coexisting with the social consequences of the construction of hydroelectric plants on the Madeira River. The research was carried out through semi-structured interviews, with the participation of 20 school agents linked to four educational institutions. The analysis of information was carried out in the light of critical references on human rights, education and psychology, through the definition of categories and subcategories. The results show that most of the school agents are unaware of the problem and that none of the surveyed schools are actively tackling the problem. Sex education is not a crosscutting issue and sexuality is reduced to the focus of risk and victimization, not being understood from a human rights perspective.
\end{abstract}

Keywords: sexual violence; children and teenagers; school.

\section{Explotación Sexual de Niños y Adolescentes: reflexión acerca el papel de la escuela}

\section{RESUMEN}

En este artículo se analiza el papel de la escuela en el enfrentamiento de la Explotación Sexual de Niños y Adolescentes, con base en un estudio realizado en unidades de enseñanza de la red pública estatal de Porto Velho-RO, municipio que en los últimos años convive con las consecuencias sociales de la construcción de usinas hidroeléctricas en el río Madeira. Se desarrolló la investigación por intermedio de entrevistas semiestructuradas, de la cual participaron 20 agentes escolares, ligados a cuatro instituciones de enseñanza. El análisis de las informaciones se realizó a la luz de referenciales críticos sobre derechos humanos, educación y psicología, por intermedio de la construcción de categorías y subcategorías. Los resultados mostraron que la mayor parte de los agentes escolares desconoce la problemática y que ninguna de las escuelas investigadas desarrolla acciones de enfrentamiento. La educación sexual no es trabajada como un tema transversal y la sexualidad es reducida al enfoque del riesgo y victimización, no entendida bajo la perspectiva de los derechos humanos.

Palabras clave: violencia sexual; niños y adolescentes; colegio.

\footnotetext{
${ }^{1}$ Centro de Defesa da Criança e do Adolescente Maria dos Anjos - Porto Velho - RO - Brasil; denisecampos86@gmail.com

${ }^{2}$ Universidade Federal de Rondônia - Porto Velho - RO - Brasil; lilian.urnau@unir.br
} 


\section{INTRODUÇÃO}

Na Conferência Mundial de População e Desenvolvimento, realizada em 1994, no Cairo, os direitos sexuais e reprodutivos foram reconhecidos como direitos humanos por 184 Estados-Parte. O Plano de Ação do Cairo (Organização das Nações Unidas, 1995a) inclui o compromisso de garantir, entre outras obrigações: o acesso a informações sobre educação sexual e reprodutiva; a prestação de serviços de saúde acessíveis, seguros e adequados à população; a implementação de políticas de segurança para coibir e eliminar todo tipo de violência e de serviços social e legais escolares, incluindo a saúde sexual e reprodutiva. Reconhece a educação, por seus efeitos positivos em todas as etapas da vida, capaz de potencializar o caráter indivisível e interdependente dos direitos humanos (Ventura, 2003).

A educação, como afirma Ventura (2003), é tanto um direito humano em si mesmo, como é um meio indispensável para realização de outros direitos. Ela pode (ou deveria) possibilitar o empoderamento dos sujeitos marginalizados, por meio da conscientização das condições de exclusão social e de todas as formas de violência. Possui um papel de grande relevância na proteção e promoção dos direitos de crianças e adolescentes, sendo a escola a instituição educativa de maior abrangência nesse sentido.

Sabemos que a discussão da sexualidade de crianças e adolescentes como um direito humano ainda enfrenta muitas resistências. Porém, vale pontuar que tanto no Plano de Ação do Cairo quanto na Plataforma de Beijing (Organização das Nações Unidas, 1995a, 1995b), ambas normativas internacionais relativas aos direitos sexuais e reprodutivos, os adolescentes foram reconhecidos como sujeitos de direitos. Portanto, eles devem ser alcançados por essas normas e pelas políticas públicas que lhes garantam, entre outras coisas, a assistência à saúde sexual e reprodutiva, bem como à educação sexual, que devem ser incluídas nos currículos escolares (Leite, 2013)

Nesse sentido, negar e não promover os direitos sexuais de crianças e adolescentes na educação escolar ou outras políticas sociais, também pode ser considerada uma forma de violência. Impossibilitar o acesso a informações e espaços de proteção a este público pode impedir, por exemplo, a coibição e ruptura do ciclo de violência sexual ao qual se pode estar submetido.

A Violência Sexual contra Criança e Adolescente (VSCCA) é considerada uma grave violação de direitos humanos porque afeta o direito ao exercício de uma sexualidade segura e plena. Trata-se de um fenômeno multidimensional, determinado por relações macrossociais e culturais e, segundo Ribeiro, Ferrarini e Reis (2004), implica articuladamente as dominações econômica, política e cultural, de gênero e de hierarquia etária.
A violência sexual se manifesta de duas formas: pelo abuso sexual intrafamiliar ou interpessoal e pela exploração sexual comercial. $O$ abuso sexual ocorre quando algum indivíduo submete uma criança/adolescente a práticas sexuais. "Envolve o emprego, uso, persuasão, indução, coerção ou qualquer experiência sexual que interfira na saúde do indivíduo incluindo componentes físicos, verbais e emocionais" (Queiroz, 2003).

A Exploração Sexual de Crianças e Adolescentes (ESCA), por sua vez, tema da análise aqui proposta, é definida pelo caráter comercial. É reconhecida como todo tipo de atividade comercial em que as redes, usuários e pessoas usam o corpo de um menino ou menina ou de adolescente para tirar vantagem ou proveito de caráter sexual (Castanha, 2008).

Exploração Sexual de Crianças e Adolescentes mantém uma relação direta com a categoria abuso sexual de natureza intrafamiliar e extrafamiliar e inclui ainda outras formas de violências. Além da exploração econômica, as violências estrutural, física, psicológica, social e moral, como também a violência simbólica, que estimula todas as formas de violência (Faleiros \& Faleiros, 2007).

O enfrentamento da ESCA e outras violências sexuais requer a implementação de variadas políticas públicas interconectadas enquanto redes de proteção, conforme discutiremos adiante, detendo a educação e mais especificamente a educação escolar um importante papel a desempenhar.

Embora compartilhemos da crítica sobre o excesso de funções extracurriculares atribuídas à instituição escolar contemporaneamente que, inclusive, limita a especificidade de sua ação educativa relativa à transmissão de conhecimentos científicos elaborados pela humanidade, partimos do pressuposto de que a sexualidade e os direitos sexuais constituem parte de tais produções acumuladas, necessárias à formação integral das pessoas em nossa sociedade, conforme buscaremos demonstrar nas seções seguintes.

Diante dessas prerrogativas, este texto, recorte de uma pesquisa mais ampla de mestrado, propõe-se a analisar o papel da escola no enfrentamento da violência sexual contra crianças e adolescentes, mais especificamente de suas ações diante da exploração sexual, em um contexto da Amazônia Ocidental, palco de grandes empreendimentos de engenharia, com a construção de duas usinas hidrelétricas no Rio Madeira em Porto Velho-RO. Cenário esse que registrou o aumento dos índices de exploração sexual de crianças e adolescentes durante as obras (Dhesca Brasil, 2011).

A escola e os direitos sexuais de crianças e adolescentes

No que se refere aos direitos de crianças e adoles- 
centes, observa-se que diferentes artigos do ECA (Brasil, 1990, com atualizações), entre os quais indicamos: Art. 5.; Parágrafo 2. do Art. 101; Art. 130; Art. 241 D; Art. 244 abordam o tema da sexualidade sob a perspectiva da violência sexual como um crime, explicitando as formas de punição aos autores e/ou partícipes. No entanto, a sexualidade considerada como um direito fundamental de crianças e adolescentes é intencionalmente omitida ou negada na legislação brasileira.

O não reconhecimento da sexualidade de crianças e adolescentes cria obstáculos para o desenvolvimento saudável desses sujeitos, visto ser ela parte integrante da personalidade de cada pessoa. A saúde sexual é um direito humano básico e, para que a criança e o adolescente tenham um desenvolvimento sexual saudável e seguro, torna-se imperativo garantir seus direitos sexuais em condições de liberdade, respeito e dignidade.

Entretanto, como observa Leite (2013), a sexualidade em geral não está colocada nas agendas dos projetos educacionais e assistenciais destinados a crianças e adolescentes e, quando aparece, apresenta-se de forma negativa, ou seja, como um "problema", a partir de uma ótica controladora dos comportamentos sexuais e reprodutivos.

Rios (2013) considera uma injustiça ignorar os direitos sexuais justamente em fases tão importantes da vida, como a infância e adolescência, em que seres em desenvolvimento precisam receber informações adequadas sobre saúde, reprodução, sexualidade, de modo responsável e sem preconceito. Devem, inclusive, aprender a reconhecer as violações que podem colocá-los em risco, até mesmo no interior do próprio ambiente familiar.

É importante destacar que o Ministério da Educação e Cultura (MEC) inseriu a orientação sexual como tema transversal, em 1997, por meio dos Parâmetros Curriculares Nacionais (PCNs) (Brasil, 1997, 1998). A proposta foi apresentada como uma maneira de trazer para a escola a responsabilidade de desenvolver uma ação educativa para a promoção da saúde de crianças e adolescentes, dividindo essa tarefa com a família.

Observa-se que, passados 20 anos da inserção da orientação sexual como tema transversal na escola, predominou no debate a preocupação com sexo, reprodução e doenças sexualmente transmissíveis, em detrimento de questões mais amplas, que envolvem a sexualidade como um direito, com foco no prazer, na autonomia, afetos, relações de gênero, responsabilidades, igualdade, liberdade, etc. (Santos, Neumann, \& Ippólito, 2011).

Nesse sentido, pautar os direitos sexuais de crianças e adolescentes como direitos humanos tem uma grande relevância, levando em consideração que convivemos com uma sociedade cuja ordem ainda é adultocêntrica e heterossexista. Defender os direitos sexuais é, portanto, defender a dignidade humana, entendida aqui como espaço autônomo de experimentação, amadurecimento e construção de seu destino, de acordo com suas preferências, seus desejos e suas tendências (Rios, 2013). Ao mesmo tempo implica enfrentar, prevenir quaisquer formas de dominação e coerção sexual, manifestas pelas diferentes violências.

Para a consecução dessa tarefa no âmbito das instituições públicas, conforme expresso no Guia Escolar (2011), a escola tem um papel preponderante, ocupando lugar estratégico no enfrentamento da violência sexual, na prevenção e no empoderamento dos alunos. É nela que se trabalham os saberes, os afetos, os valores, as normas, os modelos culturais, como também se constroem modelos de sociedade.

Ocorre, porém, que a escola não é um espaço neutro. Predomina uma determinada visão de mundo, de humanidade e de sociedade, que irá refletir-se nas relações que se estabelecem no seu interior. Ela está inserida em um contexto de profundas desigualdades expressas na totalidade da concentração de renda e de direitos, produzidas pelo sistema capitalista.

Nessa direção, é preciso configurar espaços de resistência e reflexão, uma vez que trabalhar na perspectiva dos direitos humanos significa sair do isolamento e construir coletivamente o enfrentamento, respeitando as diferenças e a pluralidade. É garantir a participação de todas as forças que compõem o ambiente da escola: diretores, supervisores, orientadores, professores, alunos e comunidade, através de um diálogo aberto na busca de soluções para os problemas, e lutar pelo melhor viver.

\section{A escola como partícipe da rede de enfrentamento à violência sexual contra crianças e adolescentes}

No momento em que a violência sexual contra crianças e adolescentes (e, mais especificamente, a exploração sexual comercial) passou a ser considerada uma questão pública e uma violação de direitos, ela se apresentou como uma demanda para as políticas públicas, reivindicada pelo movimento social em favor da infância.

O primeiro levantamento realizado em âmbito nacional sobre a exploração sexual de crianças e adolescentes, conforme consta em Silva (2014), ocorreu em 2004, com a elaboração de uma Matriz Intersetorial de Enfrentamento da Exploração Sexual Comercial de Crianças e Adolescentes, fruto de uma parceria entre a Secretaria de Direitos Humanos (SEDH), o UNICEF e o Grupo de Pesquisa sobre Violência e Exploração Sexual Comercial de Mulheres, Crianças e Adolescentes (Violes) do Departamento de Serviço Social (SER) da Universidade de Brasília (UnB).

Nesse mapeamento geossocial e político dos muni- 
cípios brasileiros, foram identificados 932 municípios e localidades brasileiras em que ocorre a exploração sexual infantojuvenil, sendo que $292(31,8 \%)$ estão no Nordeste; 241 (25,7\%) no Sudeste; 161 (17,3\%) no Sul; 127 (13,6\%) no Centro- Oeste; e 109 (11,6\%) no Norte (Silva, 2014).

Em 2011 a matriz foi atualizada com os dados do Disque 100 e apontou um número de 2.930 municípios brasileiros com registros de ESCA, ou seja, o número de casos registrados no país praticamente triplicou.

Ainda segundo Silva (2014), esse aumento deve-se à conjunção de três fatores: uma maior consciência e sensibilidade da sociedade para a denúncia; formas de identificação e registro mais eficientes; e o real aumento da incidência do fenômeno.

Por esta razão foi tão importante a aprovação do Plano Nacional de Enfrentamento à Violência Sexual Contra Crianças e Adolescentes, em 2000, pelo Conselho Nacional de Direitos da Criança e do Adolescente (CONANDA). Ele representa uma conquista da sociedade civil, que em um processo de grande articulação e mobilização com instituições públicas e com a cooperação internacional, possibilitou a construção de metodologias e estratégias de enfrentamento da violência sexual contra crianças e adolescentes.

O Plano Nacional tornou-se referência para a estruturação de políticas, programas e serviços, que articulem prevenção, atenção, responsabilização e defesa de direitos de crianças e adolescentes nos níveis federal, estadual e municipal (Tourinho \& Gomes, 2011).

Outro mecanismo fundamental para a garantia de direitos foi a institucionalização de um sistema nacional de promoção e proteção em favor da infância e adolescência. Como assinala Baptista (2012), a Resolução no. 113 do CONANDA, de abril de 2006, dispõe sobre os parâmetros para a institucionalização e o fortalecimento do Sistema de Garantia dos Direitos da Criança e do Adolescente.

De acordo com a resolução citada, esse sistema se estrutura a partir da articulação e integração em rede das instâncias públicas governamentais e da sociedade civil, a partir de três eixos estratégicos de ação na área dos direitos humanos, a saber: I - da defesa; II - da promoção; e III - do controle social. Sua competência é promover, defender e controlar a efetivação dos direitos civis, políticos, econômicos, sociais, culturais, coletivos e difusos, em sua integralidade, em favor de todas as crianças e adolescentes.

Cada eixo é composto por instituições com atribuições e responsabilidades específicas. A escola está situada no eixo da promoção. Ela é uma das instituições integrantes da rede de proteção integral e, nesse sentido, tem uma importância fundamental na prevenção da violência sexual contra crianças e adolescentes.

\section{METODOLOGIA}

A pesquisa sobre as ações de enfrentamento da exploração sexual de crianças e adolescentes desenvolvidas por escolas, foi realizada em quatro (4) instituições da rede estadual do município de Porto Velho-RO3. Com base na divisão geográfica da área urbana, optamos por pesquisar uma unidade escolar em cada zona da cidade.

O trabalho de campo foi desenvolvido centralmente por meio de entrevistas semiestruturadas com agentes escolares, realizadas com base em um roteiro de perguntas sobre a temática investigada. Ao todo, foram entrevistados 20 sujeitos: 04 (quatro) diretores, 04 (quatro) supervisoras, 04 (quatro) orientadores educacionais, 04 (quatro) professoras e 04 (quatro) alunas do ensino fundamental e médio, sendo um representante de cada segmento em cada uma das quatro escolas pesquisadas.

Desse universo, 15 (quinze) são do sexo feminino, com idades entre 14 e 51 anos. Os 4 (quatro) diretores das escolas e um orientador educacional são do sexo masculino, com idades entre 43 e 56 anos. A fim de resguardar a identidade dos/as participantes da pesquisa, as escolas investigadas serão aqui nominadas por letras do alfabeto: Zona Norte (A), Zona Sul (B), Zona Leste (C) e Zona Oeste (D). Os/as participantes serão identificados/as pela letra que corresponde a sua função, seguida da letra da escola a que pertencem ( $D$ = diretor/a; $\mathrm{S}=$ Supervisor/a; $\mathrm{O}=$ Orientador/a Educacional; $\mathrm{P}=$ Professor/a; $\mathrm{A}=$ Aluno/a).

As informações foram organizadas em categorias e subcategorias, construídas a partir de um trabalho intensivo de leitura e releitura das entrevistas, analisadas à luz de referenciais críticos sobre direitos humanos e da legislação vigente, aqui brevemente apresentados nas seções anteriores. Neste artigo, discutiremos as subcategorias: o enfrentamento da ESCA é papel da escola?; procedimentos adotados frente aos casos de suspeita ou confirmação de violência sexual; e ações de prevenção à violência sexual.

Dados os limites textuais deste artigo, buscamos, na escolha dos trechos das diferentes entrevistas e na organização das análises, apresentar um quadro mais amplo de narrativas, sentidos e opiniões, tanto em suas semelhanças/convergências, quanto em suas divergências e contradições.

\section{RESULTADOS E DISCUSSÃO}

\section{$O$ enfrentamento da ESCA é papel da escola?}

O Estatuto da Criança e do Adolescente, no artigo 70, preconiza que "É dever de todos prevenir a ocorrência de ameaça ou violação de direitos da criança e do adolescente" (Brasil, 1990, p. 22, com atualizações). Ao re-

${ }^{3}$ A pesquisa foi submetida e aprovada pelo Comitê de Ética em Pesquisa (CEP) da Universidade Federal de Rondônia. 
conhecer a importância da prevenção, o Plano Nacional de Enfrentamento da Violência Sexual Contra Crianças e Adolescentes estabeleceu como objetivo assegurar ações preventivas contra o abuso e/ou exploração sexual de crianças e adolescentes, fundamentalmente pela educação, sensibilização e autodefesa.

Nota-se, assim, a relevância que a escola assume como um espaço prioritário para o desenvolvimento de ações educativas que visem promover os direitos humanos de crianças e adolescentes.

Nos discursos dos entrevistados, contudo, observamos que poucos agentes estão cientes deste papel da escola. Nenhum deles mencionou uma ação protagonizada por essa instituição no enfrentamento da violência sexual. Pelo que disseram, a escola atua mais como coadjuvante, apoiando campanhas realizadas por outras instituições do município e/ ou acolhendo voluntários que se dispõem a debater o assunto no ambiente escolar. Analisemos a fala de dois diretores:

Na verdade, não é nem o papel da escola, porque o papel da escola é transmitir conhecimento, né? E agora estão colocando na escola todo tipo de problema da sociedade. Eu posso até estar errado... (Entrevistado DA)

A escola ela faz o trabalho de escolarização. Essa parte da exploração sexual, ainda é muito familiar. Ela não acontece na escola. (Entrevistado DC)

Esse discurso, segundo Paro (2010), vigora nos sistemas de ensino e nas políticas públicas educacionais, demonstrando uma visão estreita de educação de que o papel da escola é apenas a transmissão de conhecimentos. O autor lembra que a Lei 9.394 (1996) proclama que a educação "[...] tem por finalidade o pleno desenvolvimento do educando, seu preparo para o exercício da cidadania e sua qualificação para o trabalho" (Lei 9.394, 1996, Art. 2.ㅇ).

Todas as supervisoras escolares entrevistadas, ao contrário, reconheceram a importância de a escola atuar no combate a violência sexual contra crianças e adolescentes. Justificaram, porém, que o excesso de demandas burocráticas não permitia o planejamento dessa ação educativa, como evidenciado no fragmento a seguir:

Eu acho que a escola seria o maior aliado pra combater. Porque quando você faz, você tem a oportunidade de fazer um trabalho de conscientização, a pessoa que tem, que recebe informação, a pessoa bem informada, ela vai saber diferenciar quando a pessoa está querendo se aproveitar, quando a pessoa está querendo manipular... Sabe, é tanta burocracia, é tanta coisa que se tem que preencher, é tanta coisa que tem que se organizar e o pedagógico vai ficando... o que realmente importa vai ficando.
(Entrevistada SA)

As falas dos agentes escolares provocam uma reflexão sobre a missão da escola. Corroboro com o entendimento de Santomé (2001) que

[...] uma das finalidades fundamentais de toda intervenção curricular é a de preparar seus alunos/ as para serem cidadãos/ãs ativos/as e críticos/as". Sendo assim, ela não pode se abster de conteúdos e metas educativos do currículo que promovam conhecimentos, atitudes e valores condizentes com essa finalidade (p. 159).

O autor afirma que o planejamento do currículo deve afastar-se da visão acumulativa e bancária da escolarização e conter metas educativas que contribuam para uma socialização crítica dos indivíduos e da realidade, com vistas a uma sociedade justa e democrática.

Nesse sentido, os conteúdos desenvolvidos devem trazer as culturas ou vozes dos grupos minoritários e/ ou marginalizados que cotidianamente são silenciados nas instituições escolares, devido à forte presença das culturas hegemônicas. Como por exemplo, a cultura infantojuvenil que, muitas vezes, é estereotipada, deformada e silenciada em razão do adultocentrismo presente na sociedade (Santomé, 2001).

Dentre as quatro professoras entrevistadas, três não conseguiram responder qual seria o papel da escola no enfrentamento da ESCA, sendo que duas justificaram não trabalhar a temática em sala de aula por falta de tempo, acúmulo de trabalho, cobrança de prazos e por falta de autonomia.

A gente tem muitas turmas, muita aula. Eu dou aula de português, de inglês e de arte. Então, são muitas aulas que eu tenho pra preparar. $E$ quando eu estou dentro de sala eu estou corrigindo as produções de texto, corrigindo os cadernos, levando trabalhos pra casa, vendo como estão as relações deles. Então, a gente acaba se voltando mais para o nosso específico... (Entrevistada PA)

Chama a atenção, na maioria das falas, que a sexualidade e o direito à sexualidade são compreendidos como apêndices da escola, temas que deveriam ser abordados por funcionários da saúde, mas não como conteúdos que fazem parte do currículo, pois envolvem conhecimentos científicos e afetos.

Sobre esse aspecto, a professora da escola B foi a que mostrou ter maior clareza do papel formador da escola, entendendo que essa instituição pode ajudar os alunos a pensarem criticamente para mudar a realidade:

Porque quando a gente fala em escola, a gente fala em formar cidadãos, abrir a mente, conscientizar. E quando fala em conscientizar, a gente fala sobre vários aspectos. Acho que, em relação à 
exploração, seria a conscientização. Para que tanto o menino ou menina não se deixe ser explorado, não se deixe ser abusado, ter o valor corporal, autoestima, é isso. (Entrevistada PB)

As falas de $A C$ e $A D$ expressam de maneira mais detalhada essas demandas:

Eu acho que a escola deveria fazer mais eventos, tipo palestras, explicando as coisas, com mais frequência, entendeu? [...] Acho que deveria conversar mais com os alunos, ser menos ausente. Conversar mais não só com o 3. ano, mas com os outros também, o 3. o porque está saindo, mas igual àquela colega, ela estava com 13 anos, estava praticamente no 7. ano e estava fazendo isso. (Entrevistada AC)

Eu acho assim, tem que haver uma coisa bem tratada com uma psicóloga e eu acho também que deveria haver é mais palestras. A gente tá numa fase pela qual é adolescente já, né? [...] Os professores devem abordar mais esses assuntos, saindo um pouco da matéria, mas entrando nessa realidade... (Entrevistada $A D)$

O conjunto de respostas obtidas demonstra o distanciamento da escola frente à problemática social que envolve a ESCA. Essa posição, no entanto, não é de neutralidade. A escola, afirma Louro (1997), não apenas transmite conhecimentos, nem mesmo apenas os produz, mas ela fabrica sujeitos e produz identidades étnicas, de gênero e de classe. Atua reproduzindo a ideologia dominante, mas, às vezes, abre espaço para seu desmascaramento. Por isso, é necessário intervir para transformá-la, pois é um lugar de luta político-cultural. Freire (2003, p.112) dizia "[...] se a educação não pode tudo, alguma coisa fundamental a educação pode".

Como parte integrante da rede de proteção, a escola tem o compromisso de lutar pelos direitos humanos de crianças e adolescentes. Ela deve estimular o pensar crítico e desenvolver práticas educativas que favoreçam os/as alunos/as a atuarem de forma responsável e solidária na sociedade.

Procedimentos adotados frente aos casos de suspeita ou confirmação de violência sexual

Nas entrevistas tornou-se evidente que em casos de identificação, por agentes escolares, de violência sexual envolvendo alunos/as, a prática mais comum consiste no agendamento de uma reunião com mães/ pais ou responsáveis para conversar sobre o assunto. Entretanto, a comunicação ao Conselho Tutelar da Criança e do Adolescente, obrigatória por força de lei, nem sempre é feita. Dos 4 (quatro) diretores ouvidos, apenas o da escola $C$ afirmou ser padrão comunicar os casos, os demais disseram que procuram resolver a si- tuação internamente e, quando não é possível, acionam o Conselho Tutelar.

Entre o segmento escolar representado por supervisores e orientadores dessas escolas houve divergências quanto a essa questão. Os orientadores das escolas $\mathrm{A} \mathrm{e}$ $C$ contradisseram a fala de seus diretores, ao afirmarem que nem sempre era feita a notificação formal às autoridades. Um deles, inclusive, afirmou categoricamente que orientava os pais ou responsáveis pelo/a aluno/a, a fazerem, eles mesmos, a denúncia.

Geralmente, eu dou o telefone que a gente tem dos conselhos ou lá do juizado da infância, a gente fala onde é, manda ir lá. (Entrevistado OA)

A fala de uma supervisora escolar sobre esse assunto chamou atenção. Ela mostrou-se inconformada com o fato de a escola não notificar todos os casos e apontou uma justificativa para esta situação:

Você tem que informar aos órgãos responsáveis e a escola falha nisso porque a escola, em si, tem muito medo de assumir uma determinada responsabilidade, sabe?... Eu acho que é medo, não quer se indispor com a comunidade ou não quer estar lá, tendo que ficar respondendo, sendo testemunha... eu não sei... (Entrevistada SA)

As escolas têm um papel fundamental no combate a violência sexual contra crianças e adolescentes. $O$ ECA, no Art. 13 (Brasil, 1990, p.12, com atualizações), determina: "Os casos de suspeita ou confirmação de maus-tratos contra crianças ou adolescentes serão obrigatoriamente comunicados ao Conselho Tutelar da respectiva localidade, sem prejuízo de outras providências legais."

Ainda sobre o tema, o Guia Escolar (2011) recomenda que a escola conheça o passo a passo, as orientações sobre como fazer a notificação, o fluxo do atendimento e acompanhe os desdobramentos desse ato.

O descumprimento dessa norma por parte do estabelecimento de ensino, além de ser uma infração administrativa, provoca uma série de consequências negativas. Se os casos de suspeita ou confirmação de violência não chegarem ao conhecimento das autoridades eles não serão apurados e nem investigados. Isso, do ponto de vista da responsabilização, significa manter o ciclo de impunidade e permissividade dos autores de violência sexual contra crianças e adolescentes. No tocante às vítimas, significa a perpetuação da violência e a impossibilidade de as mesmas serem acolhidas e atendidas pela rede de proteção.

A notificação é essencial para articular os atores do sistema de garantia de direitos, a fim de promover uma ação coletiva em defesa de crianças e adolescentes vítimas do abuso e da exploração sexual. A interseto- 
rialidade e a integração das políticas públicas devem envolver, prioritariamente, a educação, a saúde, a assistência social, a segurança e a justiça.

Santos e cols. (2011) discutem no Guia Escolar que são vários os motivos que levam os profissionais a não notificarem. Um deles é a falta de percepção sobre a violência sexual e de como proceder, o que evidencia a necessidade de formação para identificação dos sinais. Outro motivo é o desconforto emocional e psicológico do educador em lidar com a sexualidade infantil e/ou com a sua própria sexualidade. É possível que muitos educadores tenham sido vítimas de violência sexual na infância e resistem às lembranças e a falar sobre o assunto.

Alguns profissionais alegam falta de tempo e acabam se omitindo; outros têm medo de se envolverem em complicações familiares e legais. Há também, aqueles que demonstram descrédito na polícia e na justiça para resolução dos casos e acham que devem resolver o assunto no âmbito escolar.

Para além da notificação, a escola tem a missão de acolher de forma atenciosa as crianças e adolescentes que revelem situações de violência sexual, identificar os riscos que ela corre e buscar adultos de confiança que possam garantir sua proteção.

"A escola poderia estar fazendo alguma coisa e não está": ações de prevenção à violência sexual

Com o objetivo de pesquisar as práticas pedagógicas desenvolvidas pelas escolas para o enfrentamento da violência sexual contra crianças e adolescentes, indagamos dos agentes escolares sobre a existência de trabalhos envolvendo a temática, projetos da escola ou parceria com outros órgãos, considerando a orientação sexual como um tema transversal a ser trabalhado em sala de aula.

Obtivemos respostas contraditórias, dentro de uma mesma escola. Por exemplo, nas escolas A e B os diretores e orientadores educacionais disseram realizarem palestras para os/as alunos/as com a participação de voluntários. Porém, as supervisoras, professoras e alunas dessas mesmas duas escolas, ao responderem sobre a questão, afirmaram que não havia nenhum trabalho específico sobre a temática. As falas de três agentes da escola A expressam essa dualidade:

[...] a escola poderia estar fazendo alguma coisa e não está, sabe? Um ciclo

de palestras, oficinas. [...] Quando você traz especialista para mostrar situações de gravidez na adolescência, pega depoimentos de meninas que já são mães, a responsabilidade, eu acho... que se mostrar pra elas, que não é brincar de casinha. Infelizmente meus colegas acham que isso é bobeira. Porque elas já sabem disso, mas não sabem. (Entrevistada SA)

[...] a gente não fez nenhum trabalho preventivo. [...] Eu nunca trabalhei o tema na minha disciplina, mas a professora de biologia, eu acho que sim. Acho que ela comentou comigo. (Entrevistada PA)

[...] na escola não. Na sala de aula já, foi um cara que chegou falando, veio de fora, não sei de onde aí. (Entrevistada AA)

Nas escolas C e D os agentes escolares verbalizaram que as ações educativas realizadas, geralmente, são palestras feitas por atores externos. Foram citados como colaboradores e/ou parceiros da escola: estudantes de faculdades privadas e da universidade pública, membros de igrejas evangélicas, equipes dos Postos de Saúde, policiais da PM, representantes do Ministério Público e Juizado da Infância e Juventude, Conselheiros Tutelares e equipes do Programa de Saúde Escolar (PSE) da Secretaria Estadual de Educação.

Entretanto, os conteúdos dessas palestras são diversos: bullying, drogas, gravidez na adolescência, doenças sexualmente transmissíveis, suicídio, depressão, violência sexual, regras básicas de trânsito, doenças de visão e verminose. São atividades esporádicas, descontínuas, pautadas exclusivamente na exposição oral de especialistas. Características que metodologicamente limitam a fala e troca de experiências entre participantes, assim como relações afetivas de confiança e cuidado. Além disso, nenhuma escola afirmou trabalhar a orientação sexual como um conteúdo curricular e transversal.

Segundo o relato dos agentes escolares entrevistados, observamos que a sexualidade na adolescência é sempre trabalhada na perspectiva preventiva para evitar a gravidez e as infecções sexualmente transmissíveis (IST). Isso significa que ela não é apresentada de forma aberta e integral, visando ao afeto, ao desejo e ao prazer. Alguns pesquisadores confirmam que a sexualidade é vista pela ótica do problema, que inclui o abuso e a exploração sexual (Nascimento \& Fonseca, 2018).

A educação sexual na escola é importante para prevenção da violência sexual, mas não pode ser orientada apenas para esse viés protetivo. É preciso ter cuidado para não reforçar uma condição de dependência e de não autonomia dos/das adolescentes.

Guastaferro (2014) destaca que as escolas precisam entender que a sexualidade faz parte do aluno/a e não se pode negá-la. Elas precisam trabalhar a temática para gerarem reflexões críticas na perspectiva de gênero e diversidade sexual, contribuindo para que alunos e alunas vivam sua sexualidade de forma saudável e refletida.

A orientadora educacional da escola $A$, ao ser questionada durante a entrevista por que o tema da sexualidade ocupava pouco espaço na agenda escolar, justificou que os alunos não manifestavam interesse: 
"eles não têm muita curiosidade, hoje com a internet ..." (Entrevistada OA).

Louro (1997), ao se referir sobre o silenciamento de questões afetas à sexualidade, supõe que isso seja uma maneira de manter a "norma". O fato de os adolescentes terem acesso à internet não significa que eles tenham a clareza suficiente para fazerem os enfrentamentos necessários para se protegerem.

A informação em sexualidade, segundo Guastaferro (2014), deve considerar uma série de concepções e cenários sociais. Ela tem que ser pensada, construída e acompanhada de sentido nessas diferentes perspectivas. Nas redes sociais, a autora diz, a informação aparece fragmentada e vai ser lida de formas diferentes e em contextos diferentes, dependendo dos recursos psicológicos e cognitivos da pessoa que leu.

A abordagem sobre um problema tão complexo, como é a violência sexual contra crianças e adolescentes e, em particular, a exploração sexual, exige preparo, conhecimento, disponibilidade e compromisso. Na fala dos sujeitos entrevistados, observa-se que a maioria nunca teve uma formação específica sobre o tema. Dentre os 20 (vinte) sujeitos ouvidos, 5 (cinco) mencionaram terem recebido apenas informações gerais sobre o assunto em seminários e/ou palestras realizados/as pelo Ministério Público Estadual.

Nesse sentido, como esperar que as instituições escolares sejam espaços de proteção e de enfrentamento da ESCA se os profissionais que nela atuam não têm conhecimento aprofundado sobre a temática e nem sequer sabem reconhecer suas causas e consequências, muito menos, que se trata de uma grave violação de direitos humanos?

\section{CONSIDERAÇÕES FINAIS}

A pesquisa demonstra que os direitos sexuais não são compreendidos na perspectiva dos direitos humanos na escola, que significa, como aponta Rios (2013), a possibilidade do livre exercício responsável da sexualidade, amparado pelos princípios da liberdade, da igualdade e da dignidade. Tampouco a escola consegue desempenhar, ou em alguns casos não compreende, seu papel no enfrentamento da violência sexual contra crianças e adolescentes.

As diversas tentativas de segmentos políticos e religiosos de impedirem o debate sobre gênero e sexualidade nas escolas reforçam a visão conservadora machista, adultocêntrica e heteronormativa da sexualidade, contribuindo para a violação de direitos do público infantil e juvenil.

O Projeto de Lei 7.180/14 (Brasil, 2014), da chamada "Escola sem Partido", ao propor alterar a Lei de Diretrizes e Bases da Educação (LDB) para afastar a possibilidade de oferta de disciplinas com conteúdo de gênero ou orientação sexual nas escolas de todo o país, é um exemplo disso.

Chegamos no final deste trabalho com a convicção de que há muito ainda por fazer no que se refere ao enfrentamento da violência sexual e, especificamente, da exploração sexual de crianças e adolescentes. Entre as diversas instituições públicas, a escola é o ator mais importante para desenvolver práticas pedagógicas que ajudem no desenvolvimento de uma vida sexual saudável. É fundamental que ela (a escola) se transforme em um espaço de pensamento crítico e abra canais de reflexão e de debate para construir uma cultura de prevenção à violência sexual e de afirmação dos direitos sexuais infantojuvenis.

\section{REFERÊNCIAS}

Baptista, M. V. (2012). Algumas reflexões sobre o sistema de garantia de direitos. Revista Serviço Social \& Sociedade, (109), 201-204. http://dx.doi.org/10.1590/S010166282012000100010.

Brasil (2017). Estatuto da Criança e do Adolescente: Lei federal no 8069, de 13 de julho de 1990, e legislação correlata (16a ed.). Brasília, DF: Câmara dos Deputados, Edições Câmara.

Brasil. (2014). Constituição da República Federativa do Brasil. Projeto de lei 7180/2014. Brasília: Câmara dos Deputados. Recuperado 16 jul. 2018. Disponível em: http://www. camara.gov.br/proposicoesWeb/fichadetramitacao?idPr oposicao=606722.

Brasil. (1997). Parâmetros curriculares nacionais: pluralidade cultural e orientação sexual, primeiro e segundo ciclos do ensino fundamental. Brasília, DF: MEC/SEF.

Brasil. (1998). Parâmetros curriculares nacionais: pluralidade cultural e orientação sexual, terceiro e quarto ciclos do ensino fundamental. Brasília, DF: MEC/SEF.

Dhesca Brasil. (2011). Violações de direitos humanos nas hidrelétricas do rio Madeira: Relatório Preliminar de Missão de Monitoramento. 37. Recuperado em 11 ago. 2020, de http://www.global.org.br/wp-content/ uploads/2016/03/r_dhescas_missao_rio_madeira.pdf

Faleiros, V. P.; Faleiros, E. S. (2007). Escola que Protege: enfrentando a violência contra crianças e adolescentes. Brasília, DF: Ministério da Educação. Secretaria de Educação Continuada, Alfabetização e Diversidade.

Freire, P. (2003). Pedagogia da autonomia: saberes necessários à prática educativa. São Paulo: Paz e Terra.

Guastaferro, C. M. (2014). É preciso repensar a concepção de educação sexual na escola. Centro de Referência em Educação Integral. Recuperado em 19 jul. 2018, de https://jornalggn.com.br/blog/centro-de-referencias-emeducacao-integral/\%E2\%80\%9Ca-sexualidade-deve-serentendida-como-direito-e-trabalhada-na-autonomia-os-i-0

Lei n.o 9.394, de 20 de dezembro de 1996. (1996). Estabelece as Diretrizes e Bases da Educação Nacional. Brasília, DF: Presidência da República. Casa Civil. Recuperado em 16 fev. 2017, de http://www.planalto.gov.br/ccivil_03/Leis/ 
L9394.htm

Leite, V. (2013). Sexualidade adolescente como direito? A visão de formuladores de políticas públicas. Rio de Janeiro: EdUERJ.

Louro, G. L. (1997). Gênero, sexualidade e educação: uma perspectiva pós-estruturalista. Rio de Janeiro: Vozes.

Organização das Nações Unidas. (1995a). Declaração $e$ Plataforma de Ação da IV Conferência Mundial sobre a Mulher, Pequim.

Organização das Nações Unidas. (1995b). Resumo do Programa de Ação da Conferência Internacional sobre População e Desenvolvimento, Cairo, Egito, 1994.

Ribeiro, M. A.; Ferriani, M. das G. C.; Reis, J. N. dos. (2004). Violência sexual contra crianças e adolescentes: características relativas à vitimização nas relações familiares. Cadernos de Saúde Pública, 20(2), 456-464. https://doi.org/10.1590/S0102-311X2004000200013

Nascimento, M.; Fonseca, V. (2018). Dinâmicas de gênero e sexualidade no contexto da exploração sexual de adolescentes: entre autonomia, tutela e invisibilidades. In Deslandes, S. F.; Constantino, P. (Eds.), Exploração sexual de crianças e adolescentes: interpretações plurais e modos de enfrentamento (1a ed., pp. 101-128). São Paulo: Hucitec.

Paro, V. H. (2010). A educação, a política e a administração: reflexões sobre a prática do diretor de escola. Educação e Pesquisa, 36(3), 763-778. https://doi.org/10.1590/S151797022010000300008.

Queiroz, K. Abuso Sexual. Conversando com esta realidade. CEDECA-BA, 2003. Recuperado em 11 ago. 2020, de http://
www.violenciasexual.org.br/texto/PDF/abuso_sexual_ katia_keiroz.pdf.

Ribeiro, M. A.; Ferriani, M. das G. C.; Reis, J. N. dos. (2004). Violência sexual contra crianças e adolescentes: características relativas à vitimização nas relações familiares. Cadernos de Saúde Pública, 20(2), 456-464. https://doi.org/10.1590/S0102-311X2004000200013

Rios, R. R. (2013). O desenvolvimento do direito democrático da sexualidade e os direitos de crianças e adolescentes. In Associação Brasileira de Magistrados. Promotores de Justiça e Defensoria Pública da Infância e Juventude (AMP) (Eds.). Violência sexual contra crianças e adolescentes: novos ol hares sobre diferentes formas de violações (1a ed., Vol. 1, pp. 19-52). São Paulo: WCF/ABMP.

Santomé, F. T. (2001). Alienígenas na sala de aula (3a ed.). Petrópolis (RJ): Vozes.

Santos, B. R.; Neumann, M.; Ippólito, R. (2011). Guia escolar: métodos para identificação de sinais de abuso e exploração sexual de crianças e adolescentes (Cunha, E., revisão geral) (2a ed). Brasília, DF: Secretaria Especial dos Direitos Humanos e Ministério da Educação.

Silva, R. A. (2014). Exploração sexual comercial de adolescentes: apreendendo o fenômeno a partir de diferentes narrativas. (Dissertação de Mestrado). Universidade Federal de Goiás, Goiânia-GO. Recuperado em 25 ago. 2016, de http:// repositorio.bc.ufg.br/tede/handle/tede/5785.

Ventura, M. (Ed.). (2003). Direitos sexuais e direitos reprodutivos na perspectiva dos direitos humanos. Rio de Janeiro: Advocaci.

Recebido: 22 de março de 2019

Aprovado: 19 de setembro de 2020 